\title{
PORNOGRAPHY AND COGNITION: A REPLY TO CASS SUNSTEIN
}

\author{
Paul ChevignY*
}

[Niels Bohr] never trusted a purely formal or mathematical argument. "No, no," he would say, "You are not thinking; you are just being logical."1

In Pornography and the First Amendment ${ }^{2}$ Cass Sunstein argues that government censorship of pornography is constitutionally permissible under the first amendment. As Professor Sunstein himself points out, his argument in favor of regulation is relatively simple." "First, pornography is entitled to only a low level of first amendment solicitude; under any standard, pornography is far afield from the kind of speech that the first amendment conventionally protects. Second, the harms that pornographic materials produce are sufficient to justify regulation."4

This reply to Professor Sunstein is not directed to the second part of the argument-that pornography is harmful — - but rather to the first. In short, this essay challenges the way Professor Sunstein categorizes pornography as "low value" speech.

As Professor Sunstein openly concedes, the structure of high and low value speech is not easy to apply to pornography under the current terms of debate. The contemporary feminist critique of pornography is rooted in the proposition that pornography is "ideological"- - that it fosters a world-view in which women are at best second-class citizens, and at worst victims. However repulsive such an ideology may be, it falls within a category of speech that seeks to persuade and thus would be

* Professor of Law, New York University School of Law. I wish to thank Bonnie Leadbearer, John Broughton, and David Lichtenstein.

1. H. Margolis, Patterns, Thinking and Cognition 1 (1987), citing D. Frisch, What LITTLE I REMEMBER 95 (1979).

2. 1986 DUKE L.J. 589.

3. Professor Sunstein defines "regulable pornography" early on: "regulable pornography must (a) be sexually explicit, (b) depict women as enjoying or deserving some form of physical abuse, and (c) have the purpose and effect of producing sexual arousal." Id. at 592.

4. Id. at 608 .

5. Questions concerning the strength of the evidence of harm upon which Professor Sunstcin relies, id. at 597-601, are considered in McCormack, Making Sense of Research on Pornography, in Women Against Censorship 181-205 (V. Burstyn ed. 1985); Linz, Donnerstein \& Penrod, The Findings and Recommendations of the Attorney General's Commission on Pornography: Do the Psychological "Facts" Fit the Political Fury?", 42 AM. PsychologisT 946 (1987). 
entitled to high-level protection. Censorship of pornography, as defined by the feminist critique, also would tend to spill over into the "viewpoint discrimination" condemned in American Booksellers Association v. Hudnut. 6

To categorize pornography as low-value speech, Professor Sunstein has to establish the claim that pornography does not make an "argument" (as we usually understand the term) in favor of its own ideological position. "Low-value" speech is characterized by four factors: (1) the speech is not directly "political;" (2) its method is non-cognitive; (3) it has a non-communicative purpose; and (4) government is unlikely to be acting against the speech for impermissible reasons. Pornography, Professor Sunstein repeatedly says, is "non-cognitive" speech since it is not directly concerned with public affairs and "cannot easily be countered by more speech." 7 Thus, in the case of pornography, the first two factors characterizing low-value speech are intimately linked to the third: the ideology implicit in pornography is not "political" and its message is largely non-communicative because pornography's appeal is "non-cognitive." Professor Sunstein analyzes viewpoint discrimination similarly, arguing that in the light of the harm of pornography, its "viewpoint" holds less significance since it is "non-cognitive" communication. ${ }^{8}$ Even though Professor Sunstein advances a number of arguments, in the last analysis the concept of the "non-cognitive" always plays a key role.

What is Professor Sunstein talking about when he refers to "noncognitive" communication? For Professor Sunstein, "the term 'cognitive' refers to whether the material is intended to or does in fact impart knowledge in any sense." $\mathrm{He}$ later states that non-cognitive speech communicates "indirectly." 10 He draws upon Frederick Schauer, who tells us: "The term 'cognitive' has a philosophical meaning restricting it to the propositional and distinguishing it from the emotive. I do not use the word in that technical sense. To react cognitively is to react mentally, or intellectually, not necessarily to 'know' a proposition."11

6. 771 F.2d 323, 332-33 (7th Cir. 1985), aff'd, 475 U.S. 1001 (1986) (city ordinance banning sale and distribution of pornographic materials as discriminatory against women held not viewpoint neutral); see also Stone, Anti-Pornography Legislation as Viewpoint Discrimination, 9 HARV. J.L. \& PUB. POL'Y 461 (1986) (advocating viewpoint neutral anti-pornography regulation).

7. Sunstein, supra note 2 , at 617 .

8. Id. at 603-04.

9. Id. at 612-17.

10. Id. at 603 n.87.

11. Schauer, Speech and "Speech"-Obscenity and "Obscenity": An Exercise in the Interpretation of Constitutional Language, 67 GEo. L.J. 899, $922 \mathrm{n} .137$ (1979) (citation omitted), cited in Sunstein, supra note 2, at $603 \mathrm{n.88}, 606$. 
Professor Sunstein recognizes that his reliance upon the cognitive/ non-cognitive dichotomy is troublesome. He confesses, at one point, that "distinctions between cognitive and emotive aspects of speech are thin and in some respects pernicious." 12 This thin distmction between cognitive and emotive aspects of speech nevertheless must sustain much of his argument. What I shall try to show here is that the distinction is considerably more pernicious than Professor Sunstein admits: it is dangerously incoherent. To reveal that incoherence, I will develop three propositions: (a) the distinction between "cognitive" and "non-cognitive" communication is contradictory; (b) if the distinction is construed to refer to an "intellectual" as opposed to another way of thinking, then it does not correspond to the way human beings approach problems, whether in society or in the natural world; (c) if the distinction is construed to mean that the "non-cognitive" aspect of speech is directly arousing without the intervention of thought, then it reflects an incoherent notion of cognition.

\section{Passion and Reason}

The term "non-cognitive" always has been polemical. Some empiricists have used the term to denounce those who refer to "emotive" subjects like values, as distinguished from matters supposedly of "determinate knowledge." 13 Professor Sunstein, however, does not have this naive usage in mind; like Professor Schauer, he uses the term "noncoguitive" more generally to provide a contrast to an appeal to the "intellect."

For centuries, philosophers have extolled the virtues of the "rational," traditionally viewed as an ability to think a question through to its conclusion in a systematic and impersonal manner. One philosophic tradition in aesthetics, upon which Professor Finnis and Professor Sunstein rely, draws upon the "detached," "objective," or "distant" contemplation of subjects of emotion. This philosophic tradition opposes "passion" to "reason," and the apparent conflict has found its way into the law. ${ }^{14}$ Professor Sunstein is not the first, nor the last, to draw on this dichotomy to support an argument for censoring expression. ${ }^{15}$

12. Sunstein, supra note 2 , at 604 .

13. See A. Lacey, Dictionary of Philosophy 37 (2d ed. 1986) (defining "eognitive"); Schauer, supra note 11, at 922 n.137 (to react cognitively is to react mentally, or intellectually, not necessarily to "know" a proposition).

14. Finnis, "Reason and Passion": The Constitutional Dialectic of Free Speech and Obscenity, 116 U. PA. L. REv. 222, 234-36 (1967) (discussing the necessity of psychologieal "distance," allowing a reasoned response, between a work of art and the observer; in contrast, pornography intrudes upon and suppresses psychologieal distance), cited in Sunstein, supra note 2, at 603 n.87.

15. See, e.g., Post, Cultural Heterogeneity and Law: Pornography, Blasphemy and the First Amendment, 76 CALIF. L. REv. 297, 328-29 (1988) (obscenity, as distinguished from pornography, 
This distinction between "reason" and "passion" also developed in psychology. Jean Piaget beheved that the development, during childhood, of a person's ability to grasp and solve physical problems ultimately would result in a level of "formal operations" in which the person would possess "the capacity to reason in terms of verbally stated hypotheses and no longer merely $\mathrm{m}$ terms of concrete objects and their manipulation."16 This psychological description of how people solve problems, however, is outmoded; it is not so much wrong as it is beside the point. For although mature people learn to reason in abstract ways in which children cannot, the "hypothetico-deductive" tools that Piaget emphasized are but the smallest part of adult thinking. ${ }^{17}$

In contrast to Piaget's assumptions about abstract thought, psychologists now recognize that "the cognitive capacity" is not unitary. Cognitive capacities mclude visual and other sorts of sensory perception, along with linguistic ways of understanding. For example, Howard Gardner has identified separable bodily-kinesthetic and musical intelligence. ${ }^{18}$ However psychologists may describe and distinguish mental capacities, the important point is that these capacities are not ordered by a capacity for "formal operations" in Piaget's sense, nor indeed by any other intellectual capacity we can identify. 19

Thinking about any subject draws on a diversity of cognitive capacities; it often involves visual imagery and other sensory cognition. For example, Albert Einstem emphasized the importance of imagery to his thought process in a description of his approach to a new problem in physics:

The words or the language, as they are written or spoken, do not seem to play any role in my mechanisms of thought. The physical entities which seem to serve as elements of thought are certain signs and more or less clear images which can be voluntarily reproduced or combined. ${ }^{20}$

may be censored because it " "pertains, not to the realm of ideas, reason, intellectual content and truth-seeking, but to the realm of passion, desires, cravings and titillation' ").

16. Piaget, Intellectual Development from Adolescence to Adulthood, 15 HUM. DEV. 1, 3 (1972).

17. Broughton, Not Beyond Formal Operations But Beyond Piaget, in BEYOND Formal OPERATIONS 395, 404-05 (M. Commons ed. 1984).

18. H. Gardner, Frames of Mind: The Theory of Multiple Intelligences 99-127, 205-236 (1983).

19. See id. at 23-27 (a "single, highly general problem-solving mechanism" cannot be brought to bear on the full range of human problems); see also J. FODOR, MODULARITY OF MIND: AN ESSAY ON FACULTY PSYCHOLOGY 119-26 (1983) (both domain specific computational mechanisms and horizontal cognitive systems exist).

20. Einstein, "Letter," in The Psychology of Invention in the Mathematical Field 142 (J. Hadamard ed. 1975), quoted in V. JOHN-STEINER, Notebooks OF THE MIND: EXPLORATIONS OF THINKING 4 (1987) (Einstein's comments used as exemplary answer to the question, "How do you think?"). 
Others, less mistrustful of verbal or written language than Einstein (for better or for worse), draw on past linguistic constructs in resolving a new problem, or merely in reviewing another's view. In this heterogeneous mix of perception and thinking, everything may be labeled "cognitive." All perception and thought aid in our comprehension of the world; the notion that some of these are "non-cognitive" because they are not "intellectual" is almost an incoherent distinction.

This point is not merely a definitional quibble. Professor Sunstein, along with other legal scholars who use distinctions like cognitive and non-cognitive, might isolate the deliberate, the intellectual, the rational capacity (supposing we could isolate it), and label it anything they like. Of course, such an exercise would only be useful if in fact such a capacity could function the way they claim it does. The problem is that it does not. Studies suggest that all people, from the most professorial to the most "intuitive," make relatively little use of "reason" in the sense described by philosophy's reason/passion dichotomy or in Piaget's notion of "formal operations." 21

A recent study is illustrative. Researchers asked their subjects to read a character sketch and then answer questions about the character. They read the following description:

Linda is 31 years old, single, outspoken, and very bright. She majored in philosophy. As a student, she was deeply concerned with issues of discrimination and social justice, and also participated in anti-nuclear demonstrations.

In answering questions, most subjects said that the proposition, "Linda is a bank teller and is active in the feminist movement," was more likely as a characterization than the proposition, "Linda is a bank teller," 22 in defiance of the basic probability that a single characteristic-like that set forth in the second proposition-is more probable than a conjunctive characteristic. The temptation to stick to the first proposition is extremely strong. In reference to this experiment, Stephen Jay Gould recently wrote: "I know that the [conjunctive] statement is least probable, yet a little homunculus in my head continues to juinp up and down, shouting at me-'but she can't just be a bank teller; read the

21. See, e.g., Tversky \& Kahneman, Judgment Under Uncertainty: Heuristics and Biases, in JUDGMENT UNDER UNCERTAINTY: HEURISTICS AND BIASES 3, 3 (D. Kahneman, P. Slovic, A. Tversky eds. 1982) [hereinafter JUDGMENT UNDER UNCERTAINTY]; R. NisBetT \& L. ROSS, Human INFERENCE: Strategies and SHortcomings OF SOCIAL Judgment 11-12, 65-192 (1980).

22. Tversky \& Kahneman, Judgment of and by Representativeness, in JUDGMENT UNDER UNCERTAINTY, supra note 21 , at $84,92-93$. 
description." "23

The point of such experiments is that people use devices of intuitive reasoning-heuristic short-cuts-in interpretimg a new social situation. These heuristics mclude (1) "representativeness," which infers causal relations from a perceived resemblance to an exemplary case; (2) "availability," which selects the most salient pattern of a problem situation to serve as an analytic framework; and (3) "anchoring," which encourages people to stick to their initial judgments and only shghtly alter them in light of subsequent evidence. The "feminist bank teller" experiment aptly illustrates all of these heuristics.

The experiments, and the heuristics they reveal, are linked to another body of psychological research involving the effort to simulate thinking by computer. These studies indicate that people use an array of "frames" or "scenarios," drawn from our past experiences (or soineone else's experiences), in addition to a vast midden of interrelated linguistic meanings (similarly understood through scenarios), to interpret even simple propositions about the social world. ${ }^{24}$

A moment's reflection reveals, I think, that this reliance on past scenarios is inevitable. The world-especially the social world-is not organized to convey meaning. Physical change or "behavior" in themselves have no self-sustaining meaning. We must orgamize our experience of the world through a host of paradigmatic narratives-exemplary tales about our own behiefs. It is these narratives that give the world a "drift" or a "go," which appears intentional in the way that narratives are always intentional. Recent analyses of the-interpretation of laws to resolve a new legal problem have reached similar conclusions; legal analysis uses a narrative scenario that exemplifies the purpose of the law in its application. ${ }^{25}$ Analogously, people's descriptions of physical laws are couched in examples that exhibit an intentional component. ${ }^{26}$ The intuitive heuristics discussed above (necessary, but dangerous) are special applications of a cognitive habit of using narrative as an organizing tool; for example, the narrative about Linda does not fit the paradigm of a bank teller. Thus the hypothetico-deductive model does not, and

23. Gould, The Streak of Streaks, N.Y. REv. OF Books, Aug. 18, 1988, at 8, 12 (review of M. Seidel, Streak: Joe DiMaggio and the Summer of (41).

24. See R. Schank \& R. Abelson, Scripts, Plans, Goals and Understanding 36-68 (1977); see also P. Chevigny, More Speech: Dialogue Rights ANd Modern Liberty 59-66 (1988).

25. R. DWORkIN, LAw's EMPIRE $65-88$ (1986); H. GADAMER, TRUTH AND METHOD 292-94 (G. Burden \& J. Cumming trans. 1975); Richards, Interpretation and Historiography, 58 S. CAL. L. REv. 489, 548-49 (1985) (proposing that "constitutional interpretation must delve into the history and nature of large cultural and political traditions, which constitutionalism express").

26. P. ChevignY, supra note 24 , at $44-46$. 
could not, describe people's thought about either new or familiar problems. The starting place for any problem is an initial judgment because, after all, no problem offers its own solution. Our emotions and our beliefs, as well as our "intellect," inform this initial judgment.

The findings of psychologists about pornography and its harm are easily adapted to this view of social judgment. In a typical pornography experiment, a male subject, often one who has been angered by a woman as part of the experiment, watches a film depicting sexual violence against a woman. The film is hikely to increase the subject's aggressiveness toward women ${ }^{27}$ because, apparently, the film cues to a scenario in which inflicting violence seems pleasurable and inhibitions against it are lifted. Thus the filin exemplifies an argument for violence against women. It is like other propaganda, and the position to which the propagandist seeks to persuade us is linked dramatically to pre-existing stereotypes. Indeed, among the most important things that the pornography experinents suggest is that powerful stereotypes about women and violence do exist. ${ }^{28}$ These experiments do not suggest, however, that the viewer's reaction to pornography (when he responds as the pornographer wishes) is esșentially different from a sympathetic viewer's reaction to other forms of persuasion.

Propaganda is powerful because it is consistent with people's way of thinking. ${ }^{29}$ We cannot escape our stereotypes through "rationality" or "detachment"; stereotypes are the principal tools for thinking that we have. Deductive thought cannot provide the patterns for comparison that our stock of narratives and examples supplies. ${ }^{30}$ The puzzle of human inquiry is that people actually come up with new patterns and sometimes change their beliefs. But they can do so only by combining existing patterns cast together in an unforeseeable way. Detached "logical" thought is not the primary mechanism for change of the beliefs that feed our intuitive heuristics; rather, our beliefs change because a combination of tales connects with our existing beliefs in a new way that we find persuasive. Creative thinking-new solutions to problems-thus cannot be radically disassociated from commonplace thinking, or even from propagandistic persuasion. The patterns of understanding that we already possess are linked to our "passions" through our beliefs, and are as essential to creative change as they are to ordinary expressions of prej-

27. See, eg., Donnerstein, Pornography: Its Effect on Violence Against Women, in PorNograPHY AND SEXUAl AGgression 53, $64-69$ (N. Malamuth \& E. Donnerstein eds. 1984) (increased aggressiveness towards women observed in three studies).

28. See Malamuth, Aggression Against Women: Cultural and Individual Causes, in PoRNogRAPHY AND SEXUAL AGgression, supra note 27, at 19, 31-32.

29. See P. Chevigny, supra note 24 , at $63-64$.

30. See id. at 63-64. 
udice. "Formal operations," as Piaget understood them, enter in to check an apercu that a person has already made through "non-formal" means-that is, through a stock of images, meanings, and other cognitive tools.

The course of cognition, from initial conception through final proof, can be illustrated in one of Einstein's thought-experiments. Einstein conceptualized one problem of relativity by imagning himself riding on a light wave and comparing his notion with the inotion of other things. In doing this, he drew upon non-verbal schemas about nature as he understood it-stereotypes or scenarios of inotion. He thus combined his kinesthetic sense and visual imagery to pose the problem by creating an apparent paradox in existing scenarios on the nature of waves versus particles; this gave him a means of comprehending the nature of light.

Einstein's originahity lay not only in his ability to imagine a problem physically, but also in his ability to construct a broader scenario that could resolve the problem. Through the special theory of relativity, he found a way to check the accuracy of his thoughts, and articulated it in a manner that could be tested again in an experiment. ${ }^{31}$ This formal stage, although important for the transmission of scientific knowledge and the falsification of theories, is not the source either of the perception of the problem or of its solution. Most important for the present discussion, Einstein did not find his solution through the type of "intellectual" argument that Professor Sunstein identifies as of "high value," but rather through a combination of scenarios about the operation of nature. Einstein followed the admonition of Niels Bohr quoted in the epigraph above: he was not just being logical, he was thinking. Although Einstein's insight and his faith in his intuition was extraordinary, his mode of "cognition" did not essentially differ from the way others make judgments about society or nature.

The reasons outlined above indicate that censorship cannot be justified on the ground that it is directed against the products of passion as distinguished from reason. ${ }^{32}$ There is no proper inethod of thinking-no royal road through logic to cognition as opposed to a low road through prejudice and passion. We may think our judgments are "detached" or contemplative, but they are as much rooted in our prejudgments as are snap decisions. More important, this dependence on prejudgment is inevitable because all of our judgnients-those that withstand the scrutiny of deductive logic and those that do not-stem from the same sources. Judgnients, moreover, can be changed only through an appeal to other

31. See, e.g., H. Pagels, Cosmic Code 23-24 (1982).

32. See H. MARGolis, supra note 1 , at 3 (recognition of patterns or attunements pre-exist and direct rational thought). 
prejudgments, which exist in patterns that are neither logical nor predictable. As Howard Margolis has said: "The tuning of patterns of response to patterns of experience [is] not just an aspect of cognition but [its] central notion." 33

\section{Short-Circuiting the Communicative}

The notion of non-cognitive speech, as Professor Sunstein and others have invoked it to distinguish pornography or obscenity, goes beyond the dichotomy between reason and passion. A colleague, who was exasperated by arguments like mine, came close to the idea by claiming that pornography is special because people "get off on it."

Professor Sunstein makes a similar distinction about non-cognitive speech: "Though comprised of words and pictures ... [pornography] is more akin to a sexual aid than a communicative expression." 34 Its appeal is non-cognitive because its "effect and intent . . . are to produce sexual arousal." 35 Professor Sunstein's point appears to be that pornography acts directly to arouse people sexually, more like a drug or physical stimulus than communication. $\mathrm{He}$ reinforces this point by analogizing pornography to "fighting words"-to a face-to-face provocation to fight. ${ }^{36}$ Professor Sunstein characterizes the experience of pornography as that of "passion" in its original sense: an experience that we "undergo" and over which we have no control.

Pornography is not the only form of expression that evokes such claims. Social commentators like to associate passion with any type of expression that they find particularly repulsive. Consider Professor Allan Bloom's comment on contemporary popular inusic: "[R]ock music has one appeal only, a barbaric appeal, to sexual desire-not love, not eros, but sexual desire undeveloped and untutored." 37

Professor Bloom also claims that rock music "has a much more powerful effect than does pornography on youngsters, who have no need to watch others do grossly what they can so easily do themselves," and that in rock music, "life is made into a nonstop, commercially prepackaged masturbational fantasy." 38

Although this example may strike some readers as silly, Professor Bloom's underlying argument parallels Professor Sunstein's argument

33. Id. A detailed argument along these lines appears in P. CHevignY, supra note 24 , at 59 .

34. Sunstein, supra note 2, at 606 .

35. Id.

36. Id. at 513-16.

37. A. Bloom, The Closing of the American Mind $73-75$ (1987). Professor Bloom probably uses "pornography" in a more traditional sense than Professor Sunstein.

38. Id. at 74,75 . 
about pornography. The implications of Professor Bloom's psychology of rock music can be characterized as follows:

Rock music presents the listener with kinesthetic stimuli that suggest sexual activity through analogous rhythmic patterns and by actual imitative sounds. At the same time, the lyrics both urge and represent sexual activity. The music thus only incidentally brings the pleasure of music, more fundamentally it arouses the listener througl kinesthetic sense. Rock music does not express erotic or sexual longing; it does not "express" anytling, but merely arouses.

Similarly, Professor Sunstein's psychology of pornography can be restated as follows:

Pornograplic film presents the viewer with visual stimuli that represent sexual activity. At the same time, the film depicts the degradation of women and connects it witl sexual pleasure. The film arouses viewers to engage in sexual activity through visual images. In the course of such arousal, it also directly arouses viewers to repeat the degradation without any intervening thought.

These scenarios representing the Bloom and Sunstein theories are incoherent. How could rock music bypass the human cognitive sense and drive a person, through some black magic, to a sexual act? Instead the music appeals to our kinesthetic sense; histeners draw a pattern from the realm of music and imagine it to be like a sexual pattern. The rest may follow from that imagination. Similarly, we do not know how a pornographic film can bypass the visual sense, and through magic arouse a person to an act of sexual degradation. Rather, viewers draw a pattern of sexual relations from their imagination and that pattern arouses. In short, neither a film nor music can bypass the imagination. ${ }^{39}$ Expression can sometimes arouse people because it enables them to picture (or perhaps verbally represent) a state of affairs that causes arousal. The curious psychological fact is that the imagination of something arousing can actually lead to arousal. This insight, however, is no different for pornography than for any other expression. ${ }^{40}$ Expression always reaches us through some imaginative pattern or patterns that we already understand, rather than through some mythical path of direct stimulation. Our ability to picture or state a scenario for action enables us to make a decision and take action.

This principle about expression becomes more clear if we reflect that "pornography" does not have the same effect on every viewer and under all circumstances. Some viewers are aroused sexually, some are revolted,

39. There is the familiar phenomenon in which a repeated rhythmic pattern may, in a receptive subject, result in a trance-like state, but it does not appear that either Professor Sunstein or Professor Bloom has that case in mind. See G. Rouget, LA Musique et LA TruSE 436-37 (1980).

40. See supra text accompanying notes 27-28. 
and some are enraged by a depiction of the degradation of women. Pornographic film scenes and still photos also can be reassembled to make a rather different piece of propaganda - an appeal against pornography in favor of censorship. Similarly, elements of racist or authoritarian propaganda can be reassembled to produce propaganda against racism and authoritarianism. Pornographic scenes thus may be arousing, but the action or belief that they arouse depends on each viewer's imagination and behefs. Pornography can be a "sexual aid" for some viewers because their imagination enables them to use it as a sexual aid.

No intelligible cognitive theory supports Professor Sunstein's assertion that pornography can cause unmediated arousal leading to degradation. Supporters of the cognitive/non-cognitive dicliotomy might nevertheless retreat to their more general argument, by claiming that the imagination-the belief-system through which arousal may be channeled-is after all not "cognition," and that the patterns of belief connected to desire, whetlier musical, visual or even verbal, are separated from the cognitive capacity. ${ }^{41}$ That position, however, is untenable because cognition does not function without the imagination. If we interpret the world of our experiences through our schemas, scenarios, and exemplary narratives, as I claim we do, then we understand events only insofar as we are able to imagine them. Tliose persuaded by pornography's ideology come to imagine the degradation of women as pleasurable just because thieir previous stock of sexual fantasies includes some scenario that corresponds to tlis ideology. Those who are offended by pornography's ideology imagine its abolition because they conceive of a sociolegal world in which suclı outrages would not be possible.

According to Professor Sunstein's conception of the problem, "the 'message' of pornograpliy is communicated indirectly and not tlirouglı rational persuasion. The liarm it produces cannot easily be countered by more speech because it bypasses the process of public consideration and debate . . ."42 But this argument merely exposes the poverty of the conception of the "cognitive" in the reason/passion dichotoniy of psychology. While it is possible to make a "direct" and abstract argument, in Professor Sunstein's sense, for pornography's subjection of women, sucl1 an argument would liave little force. Pornography's message is powerful precisely because it does not argue but represents what it lias to say in a way that arouses some of the audience. The same is true of all persuasion. For example, arguments against poverty are not powerful when they abstractly oppose economic inequality, but they gain force

41. See supra notes 13-17 and accompanying text.

42. Sunstein, supra note 2, at 616-17. 
when they enable the affluent to imagine the phight of the poor and, conversely, permit the poor to imagine a better life. Likewise, arguments denouncing society's treatment of women are powerful because they make it possible for men to imagine the plight of women and for women to imagine a different life. These arguments persuade because they arouse us (not in the sexual sense, of course) to envision action and perhaps to undertake it. That is just what it means for them to be persuasive.

Professor Sunstein's analogy of pornography with fighting words is rather misleading. ${ }^{43}$ The problem with pornography is (usually) not that it incites the viewer to action when he is with a potential victim; pornography would present a different and simpler problem in that case. Rather, pornography attempts to persuade a viewer to adopt a worldview, even when he is viewing alone. There is as much (or as little) time for responsive scenarios in the case of pornography as there is for any other compelling argument. The response is essential, however, because only answering scenarios can replace the argument implicit in pornography.

When we think about how people actually understand problems-in the sense of accepting a course of action as a solution-it is clear why most persuasive arguments have an "indirect" effect in Professor Sunstein's sense. Persuasive arguments represent a message in words and images carefully chosen to elicit a response through pre-existing beliefs. We may come to see, through the use of formal operations or other persuasive scenarios, that an argument is wrong. But we will never be persuaded unless we can imagine the world in the way the counter-argument presents it.

\section{CONCLUSION}

Why write this reply? It is certainly not an effort to support pornography, which seems to need no encouragement. According to my own approach to changing opinions, as I have outhined them, I am not likely to persuade Cass Sunstein or the others who use a cognitive/non-coguitive dichotomy, to change their views by a mere "intellectual" demonstration that their argument is incoherent and unsupported by empirical evidence. My critique requires a narrative about rights that replaces the argument that pornography is "non-cognitive" speech and that will not treat pornography as "harmless." The possibility of such a narrative is the reason for this reply.

43. See supra text accompanying note 36 . 
Pornography is not, as I have said, simply unmediated arousal. Ideologically, it is an argument by representation, like other propaganda, and it appeals only to those whose belief-systems are receptive. Like propaganda in favor of racism or violent authoritarianism, it takes hold only when stereotypes are readily available to the viewer and are accepted as "representative" of the world. Such propaganda, moreover, is dangerous for the same reasons that pornography is dangerous.

Suppressing pornography, like suppressing any other powerful propaganda, is beside the point in a cognitive world ${ }^{44}$ where we can interpret new experience only through existing patterns. An effective response to pornography must provide a different view of relations between men and women, because only such a response can replace the beliefs that sustain pornography. If expression is dangerous enough to be a candidate for suppression, then it is important enough to warrant a persuasive response.

Because of the flawed psychology that underlies it, censorship can not destroy the scenarios that underlie pornography. Only a more persuasive picture of new relations between men and women can reverse pornography's message.

44. See generally P. CHEviGnY, supra note 24 , at $53-72$ (outlining views on cognition and rationality). 